\title{
Poetas chilenos y experiencias del lugar: el lof (Mistral, Violeta Parra, Neruda, Chihuailaf y Zurita"*
}

\author{
Paula Miranda H. \\ Pontificia Universidad Católica de Chile \\ paulamirandah@gmail.com
}

Este artículo se pregunta por la forma específica en que la poesía se relaciona con la experiencia del lugar e intenta discutir la pertinencia de algunas nociones utilizadas para caracterizar esta relación. Basado en los análisis de las diversas experiencias de lugar escenificadas por la poesía fronteriza de los poetas Gabriela Mistral, Violeta Parra, Elicura Chihuailaf y Raúl Zurita, se argumentará a favor de la noción de lof como clave epistemológica y estética, la que permitirá comprender plenamente sus propuestas y dar cuenta cabal de sus respectivas experiencias del lugar, tanto éticas como estéticas, superando en cierta medida las limitaciones de las nociones de "paisaje", "poética del espacio" (Bachelard) y "tercer espacio" (Soja). Se sostiene y demuestra que para cada uno de estos poetas, habitar un espacio en el sentido del lof y darle sentido por medio de la palabra, bajo la lógica de las culturas indígenas, es lo que movilizó la mayoría de las veces cada una de sus poéticas y proyectos culturales, aunque con matices muy diversos si se les compara cuidadosamente, en especial por los disímiles contextos históricos y artísticos en que cada uno ha desarrollado su respectiva poética. Es importante aclarar que el concepto de lof ha sido tomado de la epistemología mapuche (mapu: tierra; che: gente).

Palabras claves: Poesía chilena, lof, Mistral, Parra, Chihuailaf, Neruda, Zurita.

This lecture wonders about the specific way in which poetry relates with the place experience and tries to argue the aptness of some of the notions used to characterize this relation. In base of the analysis of different place experience (experiencia del lugar) staged by the frontier poetry of the poets Gabriela Mistral, Violeta Parra, Elicura Chihuailaf and Raúl Zurita it will be argued the notion of "lof" as the epistemological and esthetic key, which will allow to fully understand its propositions and holly render account of each of their place experiences, both ethics and esthetics, overcoming in certain way the limitations of the notions of "landscape", "poetics of space" (Bachelard) and "thirdspace" (Soja). It is demonstrated that every single one of these poets inhabit a space in the sense of the "lof" and give meaning to it through their words, based on the logic of the indigenous cultures. Most of the time, this is what mobilized their poetics and cultural projects, though if you compare them carefully there are many nuances, especially because of the differences on historical and artistic contexts in which each of them developed their poetics. It is worth mentioning that the concept of "lof" has been taken from mapuche epistemology (mapu: earth; che: people).

Keywords: Chilean poetry, lof, Mistral, Parra, Chihuailaf, Neruda, Zurita.

Recibido: $16 / 04 / 2019$

Aceptado: 05/06/2019

\footnotetext{
1 Artículo realizado en el marco del Proyecto Fondap-CONICYT No 1510006 "Creación y consolidación del Centro de Estudios Interculturales e Indígenas (CIIR), del que Paula Miranda es Investigadora Asociada.

Algunos de los problemas aquí trabajados fueron abordados también, aunque con distintos énfasis y enfoques, en "Lof y palabra: poesía chilena como espacio de interculturalidad". Anales de Literatura Chilena. Sección Notas. 30 (2018): 333-342.
} 
Muy buenos días a todos y a todas. Muchas gracias a nuestra querida Gwen Kirkpatrick por reunirnos una vez más aquí en su Universidad, a compartir. Yo no soy de Berkeley ni de Georgetown, como muchos de ustedes aquí. Conocí a la afanosa Gwen a fines de los 90 cuando ella fue a mi país y consolidábamos allí los programas de género en la Universidad de Chile. Su figura me pareció cosmopolita y sofisticada, pero a la vez sencilla. Más allá de las instituciones, me fascinó y me sigue fascinando su trato cariñoso y atento, persona a persona, libro a libro, conversación a conversación con cada una de las personas que va conociendo. Me atrae la manera genuina en que escucha y se interesa por los demás. Haciéndonos sentir siempre, en cualquier parte del mundo, como si estuviésemos en casa. $Y$ de hogar $y$ palabra, de lof y poesía, es que deseo que conversemos hoy aquí.

Dividiré mi artículo en tres partes, en la primera explicaré brevemente el sentido que tiene la palabra para las culturas indígenas y cómo algunos poetas chilenos revitalizan esos sentidos (Mistral, Zurita, Neruda, Violeta Parra, Chihuailaf) y los vuelven muchas veces el centro de sus poéticas, para enseguida conectar esto con la función del habitar en un lugar específico y significativo, que aquí he decidido denominar lof y que he tomado prestado de la epistemología mapuche o del mapuche kimün.

\section{La palabra indígena, la palabra poética}

En la cultura nahuatl prehispánica el buen cantor o poeta (el cuicani), tenía una alta responsabilidad social y ética: decir palabras verdaderas era su lema, hacer sabio el rostro de los otros y fortalecer sus corazones eran su único fin; el quechua, le agregaba a su ideario la importancia de nombrar y conversar con la naturaleza, y los runas (hombres) se comunicaban a plenitud con su entorno mediante el simi o la palabra, de ahí el intento por instaurar el runasimi como la lengua oficial y única del imperio del Tahuantinsuyu. Para el pueblo mapuche, la palabra permite la conversación entre nuestro espíritu y nuestro corazón y es por ello vínculo con la naturaleza, la memoria y el sueño. Ya sea cantada, contada o conversada, la palabra tiene siempre el mismo fin: conectarnos con los otros (humanos y no humanos, materiales y espirituales) para llegar a ser personas íntegras (ser gente/ chegen) ${ }^{1}$.

En definitiva, para las culturas indígenas de cualquier lugar del mundo, la palabra en su máxima expresión, se asocia a la capacidad de hacer-crear cosas, de hacer presente la cosa por medio de la palabra. Y muchos de los poetas antes nombrados coinciden en sus propuestas con ese sentido otorgado a la palabra; aunque creo más bien, a base de datos concretos, que cada uno de estos poetas no solo coincidió con esas visiones, sino que descubrió en un momento de inflexión de sus quehaceres artísticos, estas textualidades y encontró en ellas algo que les concernía profundamente: un sentido específico para sus propias palabras y vidas, las que siempre

\footnotetext{
1 Para una amplia explicación de este y otros conceptos claves de la epistemología mapuche, sugiero consultar los imprescindibles Recado confidencial a los chilenos de Elicura Chihuailaf (Santiago: LOM Editores, 1999) y Tayiñ mapuche kimün de Juan Ñanculef Huaiquinao (Santiago: Cátedra Indígena, U. de Chile, 2018).
} 
involucran una acción en el mundo. Tanto en Mistral como en Violeta Parra, hay una clara intención por reencontrar a nivel estético, eso que cada una de ellas había vivenciado en sus infancias (Mistral en el Valle de Elqui, en zona andina) (y Violeta seis años en Lautaro, zona mapuche y de frontera). Ambas se dieron así a la tarea de estudiar persistentemente estas culturas indígenas, sus cantos y visiones, su cultura de la tierra (Mistral inicialmente en México y luego en distintas bibliotecas del mundo buscando el arawi andino; y Violeta Parra, entre 1957 y 1958, en Freire, Lautaro y Millelche, con los ül mapuche, cuya recopilación e impacto en distintos niveles de su obra, estudié detalladamente en mi libro más reciente: Violeta Parra en el Wallmapu. Su encuentro con el canto mapuche (2017). Llegó a ser tan fuerte la identificación vital con estas culturas, que Mistral se autodefinía como india y vasca y le declaró a Ciro Alegría: "Yo soy india" (41). Lo mismo Violeta, quien a partir de "El Gavilán" (1957), transgredirá productivamente su vertiente folklórica hispanista y fusionará por primera vez en la historia moderna de la música chilena, elementos poéticos y musicales mapuche, con elementos hispánicos y mestizos. Neruda será radicalmente influido para su Canto General (1950) por sus experiencias en México y Perú, según todos sabemos, y obviamente buscará reescribir La Araucana y Arauco Domado, que para él no eran solo libros, sino caminos que debían ser reescritos. Así lo declaraba en su artículo "Nosotros los indios": "La Araucana está bien, huele bien. Los araucanos están mal, huelen mal. Y los usurpadores están ansiosos de olvidar y de olvidarse" (Neruda, 272). Su Canto... es escrito en parte, para contrarrestar esa contradicción colonialista que funda nuestros Estados nacionales, y que ha excluido persistentemente los saberes, lenguas y visiones indígenas. Pero será el Pop Wuj (el libro maya quiché más conocido como Popol Vuh) donde Neruda creerá ver un "milagro....un monumento de las religiones y de la irreligión" y una mirada "a la densidad cósmica" ("Nuestra América" párr. 14, 17 ). Por su parte, la obra de Raúl Zurita sufrirá un importante giro a partir de su beca de estadía en el sur de Chile (1987 y 1988), cuando recorra fluvialmente el sur de Chile junto a Jack Schmitt y mantenga intensos diálogos con la cultura mapuche y muy en particular, con los poetas Elicura Chihuailaf y Leonel Lienlaf, y con los boteros del Sur de Chile; algunos de los cuales le relatan sus historias por medio del nütram (conversación), lo que impactará significativamente en La vida nueva (1994) y en toda su obra posterior. A partir de ello, Zurita reconocerá en él mismo una voz y una capacidad poética nunca antes experimentadas: "Mis hermanos mapuches, poco a poco me fueron devolviendo a una voz más profunda que habitaba en mí y me fue dada una cierta experiencia de la totalidad" (Prólogo, 17). Estos poetas compartieron o se identificaron con distintas aristas de estas culturas, pero aquí me referiré solo a dos de ellas: la palabra y el sentido y función del habitar en el lof, como lugar cargado de sentido para la memoria y la identidad.

Me detengo ahora solo a enumerar algunas cualidades de esa palabra que poseen las textualidades indígenas y que algunos de nuestros poetas parecen preservar. En primer lugar, la búsqueda de una palabra concreta. Ese rasgo, la concretud, que Zurita levanta como aspiración en su ensayo "Los poemas muertos", donde afirma que la poesía debe morir para que "las palabras puedan otra vez evocar y hacer cotidiana la concretud, a veces terrible, de la existencia" (86). La aspiración a una palabra que se acerque 
los más posible a aquello que nombra, mediante recursos (imágenes) plásticos, localistas, inaugurales, sensoriales y emocionales (no intelectuales, como aclara Elicura Chihuailaf). En segundo lugar, una palabra centrada en el significado, en lucha permanente por los significados. Una palabra que se vuelve más potente cuando es cantada y por eso entre nuestros poetas hay mucho "canto". Para Mistral, solo la canción se ensangrienta para aliviarla y es una "herida de amor" (203) que le abren las cosas. Cantos rituales hay en Ternura (1924), pero sobre todo en Tala (1938) y en Poema de Chile (1967). El canto quechua transfigura realidades y el mismo sujeto femenino vuelve a arder en el fuego solar de las antiguas culturas indígenas del continente por medio del canto. Neruda opta por un Canto General, pero también particular y personal: "aquí dejo mi canto" (492). En Zurita, el canto en Canto a su amor desaparecido (1985) es de carácter fúnebre, una elegía que lo vincula con los detenidos desaparecidos vía un lamento colectivo. Existen cantos fúnebres antiquísimos y modernos, y Zurita no ha renunciado a esa larga tradición (cantos de Dante, los Cantares de Pound y los del Canto General). Una palabra, además, que al necesitar ser efectiva, se realiza en diversos soportes y por diversos medios: multiartísticos y multimediales. Una palabra, además, cuyo sentido pleno se obtiene en la conversación o nütram, de ahí que Mistral pueda resolver en su Poema de Chile aquello que en Ternura (en sus ediciones de 1924 y de 1945) le había sido esquivo: la posibilidad de conversar con el "niño indio" y de que este "hablase bastante" (como ella misma lo declarara en sus manuscritos). Violeta Parra es sobre todo alguien que escucha, un oído prodigioso que "graba" noche y día, "grillos y canarios". Y lo mismo en Canto a su amor desaparecido de Zurita, donde conversan torturadores y torturados; pero también los amantes desaparecidos, los que gracias a su amor conversado, perdurarán fusionados "al mar, a las rocas y a las montañas" (12). Como dice Elicura, la palabra es un puente entre culturas y por ello "el arte de la conversación resulta hoy ser infinitamente subversivo" (Recado, 39).

Y lo más importante, una palabra, la de la poiesis, capaz de realizar una acción sobre el mundo, de agregar algo al mundo, tanto para el poeta como para su público: agradecer, ofrendar, amar, sanar. Esa dimensión ritual, está también fuertemente en Mistral, especialmente en los "Dos himnos" de Tala. Al sol del trópico, le dirá: "Desnuda mírame y reconóceme, /si no me viste en cuarenta años... iQuémame tú los torpes miedos, sécame lodos, avienta engaños;/tuéstame hablas, árdeme ojos, /sollama boca, resuello y canto" (96). Y vaya que lo dice una teósofa católica terciaria. Pero la que llevará más lejos esta dimensión ritualística y performativa de la palabra será Violeta Parra, quien en 1957 conoce a la machi mapuche María Painen Cotaro y aprende de ella la capacidad de sanar enfermos y lugares con el toque del kultrun, del canto y de las hierbas medicinales. En ese momento, Violeta decide que el propósito de su canción será de transformación del mundo mediante el arte, cueste lo que cueste: "cántale al hombre en su dolor y en su motivo de existir", nos dice en su "Cantores que reflexionan" (1966). Con su poema-canción realiza así acciones concretas respecto del mundo: agradecer en "Gracias a la Vida", transfigurarse en "Volver a los 17", sanar y sanarse en "La jardinera" o maldecir en "Maldigo del alto cielo". Y así con la mayor parte de sus canciones. Una palabra acción, que busca siempre transfigurar realidades. 
Pienso que los poetas chilenos fundamentales del siglo XX ( $\mathrm{y}$ no solo estos de los que aquí hablo) y sobre todo los poetas mapuche biculturales, que entran en escena con más resolución a partir de 1977 con El invierno y su imagen de Elicura Chihuailaf y con Horas de Iluvia de Sonia Caicheo, encarnan la continuidad de esta palabra indígena, ya sea en registros más sociales o más intimistas, ampliando y llevando a otro nivel aquello que algunos escritores o intelectuales indigenistas circunscribieron solo al problema de la representación en la primera mitad del siglo XX. Muchos de ellos adquieren por momentos una conciencia indígena desde dentro, como quería Vallejo, e impactan con esa resolución el arte contemporáneo. Más todavía, al insistir en ese gesto de afirmación identitaria y política, ellos se han convertido en puente entre culturas y temporalidades, en continuidad de memorias colectivas, un vínculo que la modernidad y el colonialismo ha intentado disociar persistentemente y que cada uno de ellos ha decolonizado con persistencia. Por eso afirma Elicura Chihuailaf en una entrevista que "Chile es un país muy importante en el plano de la palabra...(y esa palabra) podría ser un puente para el diálogo" (párr. 14, 2019) entre los pueblos.

\section{Prolegómenos del lof}

Como lo habrán ya advertido, esta es siempre una palabra alojada, situada, cosmológica (cosmología estética le llamó Raimundo Kupareo). Una palabra que reside en lugares concretos y que se enuncia desde un espacio acotado. Ecopoética, en el sentido de un quehacer vinculado a un entorno, a un lugar específico. Ya sabemos que eco viene del griego oikos que significa casa o lugar donde se vive, pues es el "ser humano" "el que como una caja de resonancia se templa, retempla y destempla según los espacios en que vive" (Sloterdijk, 18). Por ello, ni La poética del espacio de Bachelard, da cuenta absolutamente del sentido que tiene el hogar local para Mistral, Neruda o Chihuailaf; ni el concepto de paisaje permite apreciar la complejidad telúrica, antropocéntrica y dinámica que tiene la naturaleza para poetas como Neruda o Zurita. Por otra parte, el concepto de paisaje no existe en la cultura mapuche. Creo que conceptos como espacio, "paisaje" o "poética del espacio", no son lo suficientemente elásticos u obicuos como para dar cuenta de la complejidad que encierra la relación de los poetas, en sus vidas y en sus obras, con sus lugares, ya sea personales, sociales, naturales o espirituales.

Creo en cambio (pero es una hipótesis por el momento) que el concepto que concentra más íntegra y plenamente esa relación sistemática es la de lof, que tomo prestada de la epistemología mapuche y que es el sistema básico de vida comunitaria, según Sánchez Curihuentro: la unidad sociopolítica mapuche más pequeña (34) (que no se debe confundir con reducción). Para Juan Ñanculef, en su reciente libro Tayiñ mapuche kimün, el lof es la base social territorial emplazada en ocho mil hectáreas, que "permitirá el desarrollo social a escala de la naturaleza, a escala del mapu del respectivo linaje" (59). El lof está siempre liderado por un lonko y los integrantes de esta suerte de familia, se conectarán con él por medio de dos pilares básicos de su cultura: el tuwün, definido por Elicura Chihuailaf en Recado..., como aquello "anclado en el espacio físico en el cual ha nacido, crecido y se ha desarrollado la gente" (51) (el lugar donde se ha nacido) y el küpalme, que es el lazo sanguíneo que une a esa "comunidad familiar" (51). Por eso los 
apellidos en mapuzugun, significan aspectos de ese territorio específico y ser despojados de esos lugares implica, de alguna manera, perder también los nombres. La relación que ese lof mantiene con su entorno social y cultural está regulado por el Az Mapu, que es el conjunto de leyes y costumbres que rigen en distintos niveles la convivencia social, un sistema muy complejo, pero del que me interesa destacar aquí solo un aspecto muy central: el sentido de la Madre Tierra o Ñuque Mapu, de la que se viene y a la que se retorna cuando morimos. Y no se trata de algo abstracto o nominal, pues no se pertenece a cualquier tierra, sino a una tierra específica, localizada en el lugar que nos ha visto nacer y crecer de niños. Es madre-tierra porque es particular y porque de distintas madres "brotan" los diversos hijos. Cada lof pertenece a una Ñuque Mapu. Un lof entonces, que porta el sentido de pertenencia a un territorio (lugar), a una familia y una Ñuque mapu, y que determina en gran medida la forma en que vivimos, interactuamos, conversamos y afectamos nuestro entorno. Por eso Teillier afirmaba la subyugación de algunos poetas chilenos al "peso de la tierra" (49).

\section{EI lof de los poetas}

Sometimiento entonces a una ñuque mapu y a sus morfologías naturales: el Valle de Elqui y Montegrande, para Mistral; el cronotopo festivo y campesino de Chillán para Violeta Parra; el Sur Iluvioso de La Araucanía, para Neruda; la casa azul para Chihuailaf; la casona de Ñuñoa para Zurita. Pero, además, estos poetas crearon un espacio del habitar, un lof, en que el hogar de la infancia, los padres presentes o ausentes, y la búsqueda permanente de lugares de arraigo, resultó fundamental. Ahí está la lluviosa casa de La Frontera, a la que Neruda desea retornar una y otra vez. Montegrande, asociado al amor maternal y a sus cerros en Mistral. Es en su libro póstumo, Poema de Chile, donde esta mama fantasma regresará y recorrerá Chile guiada por un niño diaguita, en una conversación íntima y dinámica en busca del lof, ese que en "País de la ausencia" de Tala, parecía tan esquivo, hecho solo de fantasmas y de criaturas que vio morir, errancias y ausencias. En Poema de Chile, la sujeto pese a ser una que habla desde la muerte, reafirma su pertenencia plena a su lof en los cerros del Valle del Elqui. En el cerro sin casa del poema "Flores", es desde donde se explican las razones por las que la "mama" opta por la huerta y la naturaleza en lugar de las casas y los jardines: "Me crié/ con más cerros y montañas" (643). La creación del lof solo es posible por el acto de conversación entre niño y mama. $Y$ en ese camino, un largo recorrido por ese corredor eterno que es Chile, el yo -fantasma-Lucila y el niño indio encuentran su lof en la imagen nutricia de la huerta. Ese lugar, mapuche y diaguita, con mucho claro del ayllu andino, representa una economía de subsistencia básica, premoderna, matrilineal y que revalora la medicina y los conocimientos tradicionales como los sustentadores vitales: "-Chiquito, yo fui huertera/ ese amor me dio la mama. / Nos íbamos por el campo/ por frutas y hierbas que sanan" (Poema de Chile, 52). Lo mismo hará Violeta Parra, en "La jardinera", en donde la que trabaja la tierra no solo cura sus propias heridas de amor, sino que también las ofrece al causante traicionero de esas heridas, transgrediendo y para siempre la estructura melodramática del discurso amoroso occidental, centrado en la traición y en la pena de amor. De ahí, al sentido cósmico y bajo nuevas éticas que adquiere el amor en sus últimas composiciones, habrá solo un paso. 
Por eso el sentido más indigenista de ambas en sus primeras creaciones ("Canción quehua" de Mistral; o "Arauco tiene una pena", de Violeta Parra) signado por el no lugar; cede paso en sus últimas creaciones a un lof pleno, protector y contenido en lo indígena (Poema de Chile y "El Guillatún"). El sentido mujeril y de autogestión asociado a la huerta, será amplificado por Violeta Parra en sus Décimas autobiográficas, de 1957, donde más de la mitad de los versos se concentran en el espacio feliz de la infancia, la genealogía parriana, las jugarretas con los hermanos, la naturaleza y los trenes, la fiesta popular, la cultura campesina festiva, la casa y claro, su küpalme, padre y sobre todo madre, que alimentaron su infancia de creatividad, arte y rigor. $Y$ el nuevo nido con hijos que ella está construyendo: su lof artístico.

Lo mismo hará Elicura Chihuailaf, quien incorpora su poema "Sueño azul", fuertemente cosmológico y centrado en el lof, en sus principales publicaciones a partir de su inclusión en De sueños azules y contrasueños (1995). En este poema, Chihuailaf erige la casa azul de su infancia, como un "ser concentrado" (Bachelard, 105) y pletórico de gestos comunitarios, de pertenencia, arraigo, conexión con la Ñuke Mapu y con sus antepasados. Rememora además, el sentido de la vida y también de la muerte, mediante la reconstrucción y recuperación de su casa azul de la infancia en el lof de Quechurewe, levantada para siempre en medio de los "bosques de la imaginación" (31), de la ruka de los abuelos, de los gestos de sus familiares y de la comunidad de Quechurewe. Ese lugar será habitado por suprarrealidades, como los sueños, los recuerdos y las gestualidades de diversos seres, humanos y no humanos. En "La llave que nadie ha perdido", la propia poesía defiende su función primordial: analogarse con la conversación de la naturaleza y ser "el canto de mis antepasados" (51), creando así por medio de la palabra un küpalme que une a su "comunidad familiar".

En "La lámpara en la tierra" (el primer poema de Canto General), Neruda trasmuta el sentido dicotomizador de "civilización" (lámpara) y barbarie, "tierra", para decirnos que son justamente las claves de la tierra (vitalismo, fertilidad, renovación), las que él está dispuesto a recuperar desde el olvido: "Yo estoy aquí para contar la historia" (3). Pero junto a ese tono mesiánico y redentor, está el lof territorial, concreto, localizado, sureño, lugar que además le da el don de la palabra: entre los pájaros americanos que "acuden" en medio de la "América arboleda", todavía sin nombre ni sonidos, está la loica del Sur; y entre los ríos latinoamericanos que acuden al origen de la geología continental, es el Biobío el que le da la voz al poeta: "Pero háblame, Biobío,/ son tus palabras en mi boca/ las que resbalan, tú me diste/ el lenguaje, el canto nocturno/ mezclado con lluvia y follaje" (11). En la sección "Yo soy" el primer lugar para "habitar" no es la naturaleza en estado prístino, sino una casa, violentada por las lluvias y la humedad permanentes, una casa hecha de madera (materia) viviente y húmeda. El tercer nivel del lof son las raíces, los árboles y el agua del Sur. En repetidas oportunidades y más allá de Canto General, Neruda señaló su condición de ser austral, "pertenezco a un pedazo de pobre tierra austral hacia la Araucanía" (Antología, 395). Pero también en "Yo soy" aparecerá el tuwün (o küpalme) del lof, cuando Neruda realiza un recorrido biográfico por su infancia y juventud. En esa casa del Sur viven las imágenes de la lluvia, del bosque, de un padre siempre 
"en tránsito" y de una casa sin ciudad, situada en "la frontera": "Mi infancia recorrió las estaciones: entre/ los rieles, los castillos de madera reciente, / la casa sin ciudad, apenas protegida/ por reses y manzanos de perfume indecible" (346). Pero en esa casa de la infancia también conoció la reunión de "ferroviarios envueltos en sus mantas mojadas" (347), los que le dieron la primera imagen que él guarda de la "garra mineral de la pobreza" (347). En ese lugar, la casa de su infancia y alrededores, es posible autoconfigurar también su autorretrato "fui yo/delgado niño cuya pálida forma/ se impregnaba de bosques vacíos y bodegas" (346).

Finalmente, en La Vida Nueva, Raúl Zurita consolida algunas de las búsquedas de la primera etapa de su obra, pero clausura otras: su relación con el canto y la escritura; el modelo mítico y la relación no paisajística con la naturaleza chilena. El giro ocurre debido sobre todo a su encuentro con lo mapuche. Junto con los grandes mitos cosmogónicos de todas las culturas del mundo en los que fuimos fraguados está su küpalme, su padre fantasma, la madre y la abuela italiana, el buque Maipo donde estuvo prisionero los días posteriores al golpe de Estado; en una genealogía personal entremezclada con las erupciones de una naturaleza magnánima, con memorias geológicas y de varias glaciaciones, con la irrupción de los ríos, con muchas cosmologías, con nuestras grandes catástrofes, naturales e históricas; todo puesto en función de la creación del paraíso. Y aquí me detengo, pues pienso que el lof de Zurita, no es al igual que los poetas anteriores, un lugar, sino una estrategia de sobrevivencia y una metáfora: el paraíso lo ha llamado él, ese lugar de corrección de nuestras propias vidas:

"Como tantos, despojado, en el año 1975 inicié mi trabajo entendido como una práctica para el Paraíso, no para el cielo vacío. El inicio de ese camino se abre con el acto de haber quemado mi cara porque todavía no era posible marcar el cielo con el hecho corregido de nuestras vidas" (Zurita/Zurita, 24).

Su poesía, su canto que crea paisajes en el país, para rescatarlo de la verborrea patriotística (militar y política) y apropiárselo, es una estrategia para enfrentarse a la historia de la violencia, a la cultura del exterminio y la derrota, desde la compasión y la posibilidad de la vida nueva. Por eso todo aquí se desborda, invierte, combina y trasmuta. Por eso excede la página, y marca su mejilla, los cielos de Queens, el Desierto de Atacama. A la par casi del "Sueño azul" de Elicura, en La Vida Nueva, Zurita inscribe el escenario cosmológico en que su padre Raúl Zurita Inostroza (ya fallecido) leerá la memoria de su hijo, la memoria de las aguas (gracias en parte a Lienlaf), un sueño que permitirá vincularse con sus antepasados, con el relato mítico de diversas culturas originarias y de paso, restituirse al lugar donde todo eso ha sido inscrito: "al vuelo primordial de las estrellas". No es casual que solo cinco años más tarde, Raúl recupere plenamente su casa onírica, mezcla de recuerdo-pesadilla y sueño en su autobiografía El día más blanco.

El cambio sustancial ha ocurrido a partir de su beca de estadía en el sur de Chile (1987 y 1988) y su encuentro con los poetas mapuche Leonel Lienlaf y Elicura Chihuailaf. Mientras el primero le da las claves del canto y 
también de lo político (de la extrema violencia que nos funda y constituye, en "el hombre que hablaba con su cintura"), Chihuailaf le da el sentido de la palabra y del sueño, en sus funciones rituales y restitutivas. A ese intenso y revelador diálogo se le suman los que mantiene el poeta con los boteros del Sur de Chile (junto a Jack Smith), algunos de los que le relatan sus historias, sueños y visiones mediante el nütram (conversación). Lo que más le impacta son los mitos, de recomposición cíclica permanente. Fuerza elemental fundamental de estos ciclos de destrucción y regeneración serán aquí las aguas. La Vida Nueva, reivindica el agua como elemento vital para los hombres de la tierra, los indígenas, que dependen de ella y sus ciclos vitales para poder subsistir. Un agua que son aquí ríos que se aman y aman, que dan origen al mundo y a la circulación de la vida (arrojo), pero que también destruyen y provocan muertes. Son ríos concretos (concretud), el Yelcho, el Michimahuida, el Futalelfú, etc., parecen acentuar el carácter localista y muy específico de la memoria mítica, del lof. Por eso Raúl Zurita dice en el prólogo al libro de 1986 de Lienlaf:

Los peñis, mis hermanos mapuches, poco a poco me fueron devolviendo a una voz más profunda que habitaba en mí y tuve la certeza de que esta era una escena que volvía a vivir. Que en realidad a todos nos es dado -al menos una vez en la vida- una cierta experiencia de la totalidad, de esa "respiración del universo" (17).

Ese lugar pleno y nutricio, de restitución y pertenencia, cumple las funciones del lof. La forma de acceder a él, aunque sea aquí en la poesía, de manera metafórica, se logra por medio de la palabra. Pero no de cualquier palabra, sino de una que Elicura Chihuailaf, ha pensado "no como un mero artificio lingüístico [...] sino como un compromiso en el presente del Sueño y la Memoria" (Recado, 78), única posibilidad de conversación y reencuentro en nuestros pu lof.

\section{Obras citadas}

Bachelard, Gastón (1965): La poética del espacio. México-Buenos Aires: Fondo de Cultura Económica (1a edición en francés, 1957).

Chihuailaf, Elicura (2013): "La mapuchidad según Elicura Chihuailaf". Entr. Fernando Villagrán Revista Paula, 27 abr. Web. 1 marzo 2019. (1995): De sueños azules y contrasueños. Santiago: Editorial Universitaria. (1999): Recado confidencial a los chilenos. Santiago: LOM Ediciones.

Kupareo, Raimundo (1970): "La poesía desde su esencia". Aisthesis 5: 11-37.

Lienlaf, Leonel (1989): Se ha despertado el ave de mi corazón. Santiago: Universitaria.

Miranda, Paula et al. (2017): Violeta Parra en el Wallmapu. Su encuentro con el canto mapuche. Santiago: Pehuén.

Mistral, Gabriela (1967): Poema de Chile. Santiago: Editorial Pomaire. . (1938): Tala. Bueno Aires: Ediciones Sur.

Neruda, Pablo (1997): "La copa de Sangre". Antología Fundamental. Santiago: Editorial Andrés Bello.

(2002): "Nosotros, los indios". Para nacer he nacido (1977). Barcelona: Seix Barral. 
. (2000): "Nuestra América es vasta e intricanda". Cuadernos. Fundación Pablo Neruda 11/41: 4-13.

(1976): Canto General. Caracas: Biblioteca Ayacucho.

Ñanculef, Juan (2018): Tayiñ mapuche kimün. Santiago: Cátedra Indígena U. Chile.

Parra, Violeta (1971): Décimas. Autobiografía en versos chilenos. Santiago: Editorial Pomaire.

(1966): Las últimas composiciones, RCA Victor.

Teillier, Jorge (1965): "Los poetas de los Lares". Boletín de la Universidad de Chile 56: 49.

Zurita, Raúl (1985): Canto a su amor desaparecido. Santiago: Universitaria. . (2015): El día más blanco. Literatura Random House.

(2006): Los poemas muertos. México DF: Editorial Libros del Umbral. (1989): Prólogo. Se ha despertado el ave de mi corazón. Santiago: Universitaria. 